\title{
The Potential of Mobile Technologies for (English) Language Learning in Nepal
}

Prithivi Shrestha

\begin{abstract}
Mobile technologies have proven to be beneficial to language learners in both developed and developing countries around the world. However, they do not seem to have been exploited for language learning in Nepal although they have already been used for other purposes and their use is rapidly growing. This article proposes a number of ways that mobile technologies, particularly, mobile phones, can be deployed for language learning and teacher professional development. A number of potential challenges are also discussed.
\end{abstract}

Key words: Mobile technologies, Mobile learning, Nepal, English language learning, Teacher development

\section{Introduction}

$\mathrm{I}$ $\mathrm{n}$ this short exploratory article, I begin by briefly reviewing the current literature on mobile technologies in relation to language learning. Then, I will describe the state of play with regard to mobile technologies in Nepal, particularly mobile phones, based on desk research. Based on this, I will explore the potential and challenges of making use of mobile phones for English language learning in Nepal. I will also compare the Nepalese context with my experience of working in a large-scale international project elsewhere where relevant and appropriate.

\section{English language learning and mobile technologies}

English language learning and teaching methodologies undergone many changes over the last four decades: moving from a traditional grammar-translation method to more studentcentred methods such as Total Physical Response, Communicative Language Teaching (CLT) and Task-Based Learning (TBL) which are more popular among language teachers (see Richards \& Rogers, 2001 for an overview). CLT, in particular, appears to be appealing to many teachers. Although teachers from different parts of the world have viewed and practised CLT differently, it is widespread in the English language teaching (ELT) world. In addition to the studentcentredness of this method, communication (and hence meaning) is at its heart. In fact, CLT is all about developing learners' communicative competence in a target language(see Folse, 2010for a review). Communicative competence refers to a user's ability to use the language observing appropriate linguistic (e.g., tone, pronunciation) and non-linguistic (e.g., politeness) features while communicating a message to other users of the same language. Following this notion, CLT classroom activities are developed by drawing on real life communication (e.g., giving directions meaningfully to a tourist), which focuses on meaning making in a social context rather than learning about grammar(for a recent review, see Littlewood, 2007).

A recent surge in the use of information and communication technology (ICT) is having an impact on how English and other languages are taught and learned (see, for example Warschauer $\&$ Ware, 2008; White, 2003). The value of ICTs for language learning is widely accepted, albeit in some cases with caution(Warschauer \& Ware, 2008). In the context of developing countries, ICTs are often 
seen as an empowering tool which provides people with access to opportunities and choices that were hitherto not available. Mobile technologies, particularly mobile phones, for English language teaching and learning are still an emerging field in developing countries. But, studies in developing and developed countries do offer evidence of mobile phones' impact across various global contexts in regards to the aforementioned fields as well as other areas of development. There are many remarkable case studies outside education that highlight the efficacy of mobile phones for young peoples' participation in a radio discussion in Nepal(Ulbricht, 2010);entrepreneurial activity among women in Bangladesh (Sullivan, 2007); economic development in relation to microenterprises in Rwanda (Donner, 2007); and activism (see www.mobileactive.org) in developing countries. Of key importance to the Nepalese ELT community is leveraging the power of mobile phones, in similar ways, to provide opportunities to English language learners and potentially enhance English language teachers' professional development.

Mobile technologies have already changed the landscape of language learning in the developed countries (see, for example, Kukulska-Hulme, 2009). Unlike computer assisted language learning, mobile technologies offer learners more flexibility and mobility with regard to accessing language learning resources. For example, the learner does not have to be in one particular place. More importantly, mobile technologies break the barrier of distance between the teacher and the learner (Beckmann, 2010). Given the rapid growth of users of mobile devices such as mobile phones and media players in developing countries such as Nepal, the prospect of mobile technologies for language learning has increased over the last ten years. In fact, mobile technologies including mobile phones have already been used in Nepal's neighbouring countries such as Bangladesh, where they have been found to have a positive impact on both English language learners and teachers (Power \& Shrestha, 2010; Walsh, Shrestha, \& Hedges, 2011).

Based on the experience of working in an English language development project in Bangladesh and the available literature, I will be proposing below how mobile technologies, specifically mobile phones, may present as an attractive option for learning English. In addition, there are, of course, some challenges.

\section{Mobile technologies in Nepal}

The use of mobile technologies has phenomenally increased in Nepal over the last ten years. Until about a decade ago, mobile devices such as laptops and mobile phones were seen in the hands of the elite only. This is not the case any more. In particular, the penetration of mobile phones is remarkable. According to Nepal Telecommunication Authority(NTA, September 2011), of the total 13.513 million fixed and mobile telephony subscribers, mobile phone users constituted 11.919 million $(88 \%)$ in August 2011. This is a strong indication of the tremendous popularity of mobile phone use. Such high penetration of mobile phones certainly means more opportunities for mobile learning. Mobile learning is a tricky term (Kukulska-Hulme, 2009). In this paper, it refers to the mobility of technology, content, and learners in the context of learning. There have already been calls for tapping into mobile phones for educational use in Nepal (e.g., Ghimire, 2011).

Mobile technologies seem to have already been employed for various purposes in Nepal. For example, in April 2010, UNICEF Nepal launched a programme called Voices of Youth in collaboration with a popular Nepali radio programme called 'Sathi Sanga Manka Kura' which targets young listeners aged $13-26$ throughout the country (Ulbricht, 2010). This programme allows listeners to participate in the discussion on important topics related to them and express their views via text messages (i.e., SMS) in English. A most recent topic for discussion (25 October 2011) was 'Can Love and education go hand in hand? If yes, how? If no, why?' (see http://www.unicef.org.np/ voy/can-love-education-go-hand-hand-if-yes-howif-no-why for real responses). This is an excellent example of the use of mobile phones that enabled those who had no say until recently.

Likewise, given the growing market of the mobile phone use including mobile data (e.g., General Packet Radio Service, GPRS in short), the development of mobile applications (also known as apps in short) seems to be growing as indicated by recent conferences such as Mobile 
apps development in Nepal, in September 2011 (see http://mobilenepal.net/events/mobile-appsdevelopment-nepal-0 ). Although mobile apps are developed for other purposes such as banking and finance, this may create an opportunity to develop an English language learning app if appropriate resources are available.

\section{Prospects of mobile technologies for language learning in Nepal}

As noted earlier, mobile technologies have been used increasingly in language learning in the developed world. The use of mobile devices for this purpose in developing countries is growing too. Nepal is not an exception. There has already been some exploration with regard to the use of mobile devices for English language learning. For example, an exploratory study was carried out with English teachers in eight state schools in Chitwan District (mid-southern part of Nepal) in relation to the digital content (Shrestha, Moore, \& Nocera, 2011). The initial findings suggest that having access to digital content (i.e., English language materials) via offline mobile devices such as a pocket-size computer called Ben Nanonote (see https://sharism.cc/ ) and an open-source handheld Wikireader (see https://www.thewikireader. com/ ) made teachers' lives a lot easier.

Likewise, the British Council in Kathmandu launched Learn English Mobile in Nepal in September 2011(BC, n.d.). The content is being delivered by a company called Focus One Nepal which specialises in software development and related services. The English language materials are sent to learners via SMS and Interactive Voice Response (IVR). Typically, people have to send a text message or make a call to a particular number to get any materials such as vocabulary related to tourism or practise certain expressions in English. The British Council states that 'Mobile phone offers the most portable and affordable means to learn English. The concept is much more economical and adaptive than formal methods' (see http://www.britishcouncil.org/ nepal-english-learn-english-mobile.htm ). This project aims to target foreign jobseekers and those engaged in tourism sector, and reach 3 million people in Nepal by the end of 2013. In fact, a similar initiative was launched in November 2009 in
Bangladesh as part of the English in Action (EIA) project (seehttp://www.eiabd.com/eia/ for more on EIA). The initiative reached 3.5 million people through mobile phones in Bangladesh who never had access to English before.

Although there is no hard data if most teachers and learners (or the household) own a mobile phone in Nepal, I have assumed that a good number of teachers possess one and also about two fifths of learners, particularly secondary, have access to mobile phones. Given the potential of the mobile phone suggested above and my own experience of working in the EIA project and elsewhere, now I would like to propose a number of possibilities for both English language learners and teachers below.

\section{English language learners}

There are a number of ways that mobile phones can be employed for English language learning. In particular, learners have to read text messages in English which they do anyway (even if in Roman) because there is no Devnagari script/ characters on the phone. The following techniques have been tried elsewhere and can be adopted in Nepal too.

\section{Text messages (SMS)}

Learners can be sent vocabulary via SMS. This may take the form of one word or expression a day/ week and its use in a context (e.g., sentence). For example, if it is in a formal education context, the teacher can send the words taught the previous day/ week as revision. In an informal context, such SMS services could be provided at a very cheap rate on demand like the one successfully done in Bangladesh through the BBC Janala initiative in the EIA project mentioned earlier (see http:// www.eiabd.com/eia/ ) or like the one launched by the British Council Kathmandu. Another possibility is sending short quizzes to learners for the revision of any aspect of English language.

\section{Voice response}

People have been using mobile phones in their everyday life to make voice calls. Of course, it is generally in Nepali or any other local languages in the country. In collaboration with mobile phone service providers, organisations such as NELTA working with other organisations could 
offer voice response services to people wanting to learn English from all over the country. For example, people could dial a specific number and choose from the menu what they want to learn (e.g., pronunciation, vocabulary, etc.) and practise their English at a very low cost rather than going to a private tuition centre which is far more costly than making a call. This provides more flexibility and mobility to learners, which is impossible in the context of formal methods of learning English. Most importantly, the responsibility of learning rests on the learner, thus making mobile learning much more learner-centred than other approaches of learning.

Many mobile phones have in-built voice recorders. Learners can use them to record their own voice/ conversation. They can then share the recording with others and discuss it.

\section{Mobile content (online and offline)}

In addition to text messaging and voice response, it is possible to provide English language learning content (classroom and professional development materials) via mobile phones (Walsh, et al., 2011). The content can be both audio and video which is generally supported by even the low-cost mobile phones such as Nokia C1-01 (see http://pricenepal. com/nokia-mobile/576-nokia-c1-01.html ). In fact, Nokia C1-01 was tested with English language teachers in Bangladesh as part of the EIA project and was found to be an effective mobile device that could store audio and video contents on a memory card, and play them back. The quality was very good despite the device being cheap. This is possible to do in Nepal too. It is a matter of producing English language learning contents that suit Nepalese learners of various levels. Some English language learning materials available on the web could also be deployed for this purpose. Some advanced phones including smartphones also support written texts. They can be used to store and display written learning materials. In addition, some phones contain English language dictionaries, which learners can use when needed.

Furthermore, accessing internet ormobile data via mobile phones has dominated the internet service in Nepal. For example, 3.144 million of the registered 3.276 internet users access the data via their mobile phones or CDMA2000 according to the latest report published by Nepal Communication Authority (NTA, September 2011). Although these users may be limited to the urban area such as Kathmandu and other cities, the potential of offering mobile language learning materials is high. Possibly, many people already do so given that most of the information on the internet is available in English. NELTA and other organisations could start a venture into this market. One possible way is podcasting which could focus on specific aspects of English language. This could even be made bilingual, using both English and local languages. In addition, many mobile phone users listen to the local FM radio. As NELTA has already produced and broadcasted English language programmes via FM radio stations, it is a matter of continuing such programmes and perhaps targeting young adults.

\section{English language teachers}

Like learners, teachers too benefit from mobile language learning in similar ways as described below.

\section{Text messaging}

Text messaging has been used effectively for teacher professional development elsewhere (e.g., Walsh, et al., 2011). For example, it has been used to build an English language teachers' network, to remind teachers of forthcoming teachers' cluster meetings and to send questions for discussion in the EIA project in Bangladesh. Teacher mentors could use a similar method on a regular basis, which may have already been happening.

Likewise, English teachers can use text messaging to remind their students of homework, vocabulary, etc. This may make learning less formal and more meaningful as using mobile phones is part of everyday life unlike learning in the classroom.

\section{Voice response}

Voice calls provide another opportunity to English teachers to develop professionally. For instance, they can make calls to any other English teacher or mentor to discuss any issues related to their teaching. They can also share their good practice (e.g., a good lesson) with others, thus helping others to develop. In the past, it was not possible unless teachers were prepared to meet physically 
or called from a landline. This would, nevertheless, have lost the immediacy provided by the mobile phone.

Likewise, mobile phones with the recording facility offer teachers to record their own or their learners' voice in English. This could offer new learning materials. Furthermore, many basic mobile phones tend to have cameras (both photo and video) which could be used to develop authentic materials for classroom use.

\section{Mobile content}

Teacher development materials for mobile devices including mobile phones have successfully been developed and used in developing contexts (Shrestha, et al., 2011; Walsh, et al., 2011). For example, Bangladeshi primary and secondary English language teachers are provided with audio and video materials for professional development and classroom use via Nokia C1 - 01 mobile phones through the EIA project. Therefore, it is timely that Nepalese English language teachers have access to such materials. As noted earlier, even a cheap mobile phone supports audio and video content, and thus this capacity of mobile phones empowers teachers as they can access really good quality materials at a fraction of the cost that often incurs in traditional teacher training programmes. These days, such materials are often available as Open Educational Resources on the website. Teachers having access to the data service could easily download them. Of course, any mobile data usage has cost implications (see Section 5 below).

\section{Challenges}

The educational use of mobile technologies is, however, not without challenges. These challenges relate to resources, contents and socio-cultural context as explained below.

\section{Resources}

First of all, the biggest barrier to any change is the availability of resources for implementing it. In the context of mobile language learning, resources include mobile devices, human capacity to create, repurpose or adapt materials, and funding if needed. Mobile learning obviously means having access to mobile devices such as mobile phones. Although they are often labelled as 'ubiquitous' in developing countries as well, they are not affordable to everyone. This limits the access to mobile learning by those without mobile devices. Most importantly, the cost of text messaging, voice calls and mobile data service may deter people from using mobile phones.

Despite mobile learning being appealing, human resource that is capable of producing appropriate mobile learning materials can be a hurdle too (see Section 5.2 as well). For example, it does not appear that there has been any initiative to create materials for mobile platforms except the digitised versions of textbooks for schools (see E-Pustakalaya onhttp://www.olenepal.org/ as an example). However, these materials cannot be used on mobile phones except smartphones. Therefore, ELT community in Nepal is yet to develop human resources (or humanware) that are able to produce mobile learning materials.

Related to human resources are funding initiatives that focus on mobile language learning. Nepalese ELT community is certainly not short of experts who can invest their energy and expertise in mobile learning materials. However, as a new area of educational development, the initiative requires time from people and other resources which are not readily available. For this the government needs to develop policies as to how to exploit opportunities offered by mobile technologies, probably drawing on the experience of the other South Asian countries.

\section{Content}

As mentioned in the previous section, there are probably no language learning contents that readily suit mobile phones for use by teachers or learners in Nepal. Therefore, even if they have mobile phones, there are no contents or the available content may have no direct relevance to users' needs. Since creating content is not a single person's job, a concerted effort from both professional organisations such as NELTA, and the government is needed. Nepal can possibly learn from her neighbours such as India and Bangladesh where the government has launched initiatives with regard to technologies (e.g., Digital Bangladesh - http://www.digitalbangladesh.gov. $\mathrm{bd} /$ ). 


\section{Socio-cultural context}

Socio-cultural contexts play a central role in implementing any educational change. In particular, the perception oflearning and education is important here. The relationship between the teacher and the learner has traditionally been hierarchical, teachers being the knowledge provider and learners being the receiver. As mobile learning may put more power on the learner, there may be resistance from teachers to the new way of learning. In fact, the Department of Education in Nepal has issued a notice banning the use of mobile phones by students in all schools including higher secondary schools as reported in the media (see Sharma, 2011). This is an indication that mobile phones have not been used judiciously in schools. Furthermore, learning is often seen as formal and therefore, both teachers and learners may not notice the benefit of mobile learning which may happen informally outside the classroom. However, these socio-cultural challenges may be overcome if mobile phones are employed for language learning purposes as proposed in this article.

\section{Conclusion}

In this brief article, I explored what affordances mobile technologies have and how they can be exploited in the context of English language teaching and learning in Nepal. I also proposed a number of ways of using mobile phones for language learning and teacher professional development given the high penetration of mobile phones in the country. Of course, these are not easy to put into practice as there are many challenges that relate to resources and the specific sociocultural context of Nepal. Despite the challenges I have described above, mobile technologies do offer opportunities to both English teachers and learners if a concerted effort is made by both professional organisations and the government.

\section{The Author}

Prithvi Shrestha is Lecturer of English Language Teaching at OpenELT, Department of Languages, The Open University, UK. He taught English in both primary and secondary schools in Nepal for over 12 years until 2002. He has been working in the UK higher education sector for over eight years. His specialisation includes designing and writing academic literacy courses for open and distance learning, mobile learning materials for English language teachers and learners in both developed and developing countries. His research interests include mobile learning in development contexts, language assessment, teacher education and academic literacies. He has published a number of books, book chapters and journal articles.

\section{References}

BC. (n.d.). Learn English Mobile in Nepal Retrieved 31 October, 2011, from http://www.britishcouncil. org/nepal-english-learn-english-mobile.htm

Beckmann, E. A. (2010). Learners on the move: mobile modalities in development studies. Distance Education, 31(2), 159-173. doi: 10.1080/01587919.2010.498081

Donner, J. (2007). The use of mobile phones by microentrepreneurs in Kigali, Rwanda: changes to social and business networks. Information Technologies and International Development, 3(2), 3-19.

Folse, K. (2010). Communicative Competence and Grammar Classes Revisited: 1980 and 2010. Contact, 36(2), 7 - 19.

Ghimire,B.(2011,25 August 2011). Nepal: opportunities and challenges for mobile education Retrieved 31 October, 2011, from http://futurechallenges.org/ local/nepal-opportunities-and-challenges-facingmobile-education/

Kukulska-Hulme, A. (2009). Will mobile learning change language learning? ReCALL, 21(2), 157-165.

Littlewood, W. (2007). Communicative and task-based language teaching in East Asian classrooms. Language Teaching, 40(03), 243-249. doi: doi:10.1017/S0261444807004363

NTA. (September 2011). Management Information System report (Vol. 82). Nepal Communication Authority, Kathmandu.

Power, T., \& Shrestha, P. (2010, 19 - 21 March 2010). Mobile technologies for (Eglish) language learning: an exploration in the context of Bangladesh. Paper presented at the IADIS International Conference: Mobile Learning 2010, Porto.

Richards, J. C., \& Rogers, T. (2001). Approaches and Methods in Language Teaching. Cambridge: Cambridge University Press.

Sharma, N. (2011, 3 August 2011). Government bans cell phones, junk food in schools, eKantipur. com. Retrieved from http://www.ekantipur. com/2011/08/03/capital/government-bans-cellphones-junk-food-in-schools/338452.html 
Shrestha, S., Moore, J., \& Nocera, J. A. (2011). Opensource platform: exploring the opportunities for offline mobile learning. Paper presented at the Proceedings of the 13th International Conference on Human Computer Interaction with Mobile Devices and Services, Stockholm, Sweden.

Sullivan, N. P. (2007). Can You Hear Me Now? How Microloans and Cell Phones are Connecting the World's Poor to the Global Economy. San Francisco, CA: Jossey-Bass.

Ulbricht, M. (2010, 17 June 2010). Voice of Youth Retrieved 03 November, 2011, from http://www. mobileactive.org/case-studies/voices-youth

Walsh, C. S., Shrestha, P., \& Hedges, C. (2011). Leveraging Low-Cost Mobile Technologies in Bangladesh: A Case Study of Innovative Practices for Teacher Professional Development and Communicative English Language Teaching. In R. Kwan, C. McNaught, P. Tsang, F. L. Wang \& K. C. Li (Eds.), Enhancing Learning Through Technology. Education Unplugged: Mobile Technologies and Web 2.0 (Vol. 177, pp. 152-166): Springer Berlin Heidelberg.

Warschauer, M., \& Ware, P. D. (2008). Learning, change, and power: Competing discourses of technology and literacy. . In J. Coiro, K. M., C. Lankshear \& D. J. Leu (Eds.), Handbook of research on new literacies (pp. 215-240). New York: Lawrence Erlbaum.

White, C. (2003). Language learning in distance education. Cambridge ; New York: Cambridge University Press. 